\title{
Medicina laboratorial baseada em evidências: o patologista clínico deve conhecer esse instrumento
}

O exame de fator antinuclear (FAN) continua merecendo a atenção especial de profissionais de laboratório. Em nosso último número, tivemos a oportunidade de conhecer o III Consenso Nacional para Pesquisa de Autoanticorpos em Células HEp-2. No volume presente, também trazemos um interessante artigo: "Taxa de probabilidade (likelihood ratio) como guia de interpretação do FAN-HEp-2 na pesquisa de autoanticorpos no lúpus eritematoso sistêmico"(1). Nele, os autores utilizam ferramentas estatísticas para avaliar o impacto da pesquisa de autoanticorpos para o diagnóstico do lúpus eritematoso sistêmico (LES) e outras doenças autoimunes e concluem que, considerando a sensibilidade e a especificidade do teste de FAN para resultados distribuídos em diferentes intervalos, aqueles com baixos títulos não modificam significativamente a probabilidade pós-teste da ocorrência da doença. Assim, mais uma vez, reforça-se que a probabilidade pré-teste de autoimunidade é um dos fatores que mais influenciam o desempenho diagnóstico do FAN. Escrito de forma didática, o artigo ainda apresenta, aos não-iniciados em estatística, conceitos fundamentais de sua utilização na medicina laboratorial baseada em evidências (MLBE). A MLBE envolve todo o processo de tomada de decisão do médico, partindo da probabilidade pré-teste, definida pela história clínica do paciente, passando pelos resultados dos exames e o respaldo científico de seus parâmetros estatísticos, e finalmente definindo o impacto do exame laboratorial no diagnóstico de uma determinada condição.

A publicação desse artigo veio em momento propício. Recentemente, a Sociedade Brasileira de Patologia Clínica/Medicina Laboratorial (SBPC/ML) traduziu para o português, mediante acordo com a Sociedade Italiana de Medicina Laboratorial (SIMel), a página eletrônica e-Thesaurus. Trata-se de um recurso importante da MLBE que merece ser divulgado e explorado. Para acessar, deve-se dirigir ao endereço eletrônico da SBPC/ML, www.sbpc.org.br, onde está o link e-Thesaurus MLBE.

Em 2003, o JBPML apresentou, em seu editorial, as palavras do Dr. Álvaro Rodrigues Martins e da Dra. Luisane Maria Falci Vieira, que comunicavam que, entre as principais metas da SBPC/ML estava catalisar o uso das ferramentas da medicina baseada em evidências por nossa especialidade e, por meio da MLBE, contribuir para a melhoria da efetividade da medicina brasileira( ${ }^{(2)}$. Em sequência, o 39을 Congresso Brasileiro de Patologia Clínica/Medicina Laboratorial (CBPC/ML) teve como tema central "A evidência científica a serviço da gestão em saúde".

Recentemente, no 43 CBPC/ML, o Dr. Murilo Rezende Melo proferiu a palestra "Medicina laboratorial baseada em evidências: como utilizar a nova ferramenta traduzida pela SBPC/ML para aumentar a segurança diagnóstica" e, elegantemente, apresentou à plateia o passo a passo para valer-se desse novo instrumento de auxílio tanto para os patologistas clínicos como para os médicos solicitantes.

Fazemos aqui um convite para que os leitores visitem a página eletrônica e-Thesaurus da SBPC/ML e tornem-se usuários frequentes. Os pacientes agradecem.

Silvana Maria Eloi-Santos

Editora da SBPC/ML

\section{Referências}

1. BECK, S. T. et al. Taxa de probabilidade como guia de interpretação do FAN-HEp-2 na pesquisa de autoanticorpos no lúpus eritematoso sistêmico. J Bras Patol Med Lab, v. 45, p. 275-83, 2009.

2. MARTINS, A. R.; VIEIRA, L. M. F. Medicina laboratorial baseada em evidências: subsídio para melhores práticas clínicas. J Bras Patol Med Lab, v. 39, n. 4, 2003. 